\title{
Impact of Fund Size on Hedge Fund Performance
}

Manuel Ammann

Patrick Moerth

Working Paper Series in Finance

Paper No. 11 


\title{
IMPACT OF FUND SIZE ON HEDGE FUND PERFORMANCE
}

\author{
Manuel Ammann, Patrick Moerth \\ Swiss Institute of Banking and Finance \\ University of St. Gallen \\ Rosenbergstrasse 52 \\ CH-9000 St. Gallen \\ Switzerland
}

May 2004, revised January 2005

Keywords: Hedge funds, performance measurement, size

Manuel Ammann is professor of finance; Patrick Moerth is a hedge fund analyst at Credit Suisse and a Ph.D. student at the University of St. Gallen. Contact details are Tel: +4171-224-7090, Fax: +4171-224-7088, email of corresponding authors: manuel.ammann@unisg.ch, patrickmoerth@yahoo.com 


\begin{abstract}
In this article we investigate whether the increase in assets flowing into the hedge fund industry diminishes returns and, in particular, whether larger hedge funds underperform smaller hedge funds, as is often conjectured due to limited capacity in certain hedge fund strategies. The impact of fund sizes is analyzed with respect to fund returns, standard deviations, Sharpe Ratios and alphas derived from a multi asset class factor model.
\end{abstract}

In the last years hedge funds have gained a widespread acceptance due to their interesting risk-return characteristics and their low correlations to traditional asset classes. Many studies have investigated the factors impacting hedge fund returns. The factors vary between the different hedge fund strategies and, additionally, the variety of strategies is increasing in the hedge fund industry. At the same time, the hedge fund industry has experienced impressive growth such that capacity is becoming a serious issue not only for large hedge fund investors that are looking for investment opportunities to employ the capital, but also for hedge fund investors that are looking for good hedge funds that are open for investment. Increasing efficiency of financial markets results in decreasing arbitrage opportunities that are the primary source for returns of some hedge fund strategies. In this paper, we investigate whether an increasing asset base of hedge funds is diluting performance.

On one side we can conjecture that small hedge funds are underperforming larger hedge funds due to a higher expense ratio. On the other side many investment professionals argue that smaller funds are outperforming larger funds due to a higher risk appetite or their enhanced flexibility to concentrate the capital under management on their best investment ideas. The best ten investment ideas of a hedge fund manager are generally better than the best 100 ideas. Smaller hedge funds are also more nimble and therefore more liquid due to smaller position sizes. Large funds may face difficulties in liquidating their positions in difficult market environments.

We find that some studies are touching the subject with varying results. While the effect of fund size on performance is one of the largest concerns in the hedge fund industry it has received little research attention of studies exclusively focusing on this subject. This article attempts to fill this gap by evaluating the relationship between fund sizes and performance 
from different angles. The study is supported by empirical evidence based on a large data sample of hedge fund returns and fund sizes.

A number of different multi asset class factor models have been used to derive alphas of hedge fund returns. In contrast to the standard asset-class factor model of Sharpe [1992] we use excess returns to derive alphas from our factor models in order to investigate the impact of fund sizes. Our empirical study provides some evidence for a positive relationship between fund sizes and hedge fund performance.

The structure of the paper is the following: We start with a literature overview, followed by a description of the data set used for our analyses. Next, we introduce the methodology and an empirical analysis concerning the impact of fund sizes on hedge fund returns, standard deviations, Sharpe Ratios and alphas.

\section{LITERATURE OVERVIEW}

Several authors propose factor models to explain hedge fund returns. Fung and Hsieh [1997] employ Sharpe's [1992] model and use a principal component analysis to explain hedge fund returns. Agarwal and Naik [2000] develop a factor model and point out the nonlinear option-like exposures of various hedge fund strategies. An interesting approach to overcome the short history of hedge fund returns has been proposed by Agarwal and Naik [2002]. The authors use the underlying risk factors estimated with a multi-factor model to simulate the effects of the major stock market crises of 1929 and 1987 on hedge fund returns. Schneeweis, Kazemi and Martin [2003] investigate the differences between a single factor and a multi factor model to explain hedge fund strategy returns. Brealey and Kaplanis [2001] investigate changes in factor exposures to explain hedge fund returns over time.

Clark [2003] provides a comprehensive study about the relationship of fund assets and performance for mutual funds and concludes that no significant return differences can be found between small and large funds on a variety of holding periods from 1991 through 2001. Herzberg and Mozes [2003] investigate the impact of several factors on hedge funds performance and find that smaller hedge funds display a performance that is slightly better and barely significant compared to larger funds, while the difference is positively significant regarding Sharpe Ratios.

Hedges [2003] shows that smaller funds outperform larger funds, but finds that mid-sized funds perform the worst. This phenomenon is explained with the concept of mid-life crises for hedge funds managers. 
Gregoriou and Rouah [2003] find no correlation between the size of hedge funds and their performance. The relationship is tested with Pearson's correlation coefficient and Spearman's rank correlation from January 1994 to December 1999. Using the geometric mean, the Sharpe Ratio and the Treynor Ratio, the correlations are not statistically significant. The sample is composed of 204 hedge funds and 72 funds of hedge funds and is therefore significantly smaller than in our study and not necessarily representative for the hedge fund industry.

Edwards and Caglayan [2003] argue that hedge funds performance increases at a declining rate as fund sizes increase. The authors derive six-factor alphas from a similar framework than that of Fama and French [1993, 1996]. The six-factor alphas are then regressed on five variables: size, the reciprocal of size to capture nonlinearity in the sizeperformance relationship, age, and both management and incentive fees. Both size variables are statistically significant for all hedge funds and for all investment styles except "global macro" and "global". A positive coefficient on the size variable together with a negative coefficient on the size reciprocal variable indicates that hedge funds performance increases at a declining rate as fund sizes increase.

Liang [1999] investigates the impact of fund characteristics with a cross-sectional regression and finds a significant positive relationship between fund assets and performance. The assets of the funds are taken only from one point in time at the end of the period. Therefore the result may simply suggest that successful funds attract more money over time and therefore have a positive correlation to past performance. The study does therefore not necessarily measure the impact of fund assets on performance, but the impact of performance on fund assets. The data set used contains only 385 funds investigated over a three years time horizon from January 1994 to December 1996.

Amenc and Martellini [2003] support the view by investigating two equally sized groups with large and small funds. For each group, the average alpha is computed based on a number of different models, such as the standard CAPM, an adjusted CAPM for the presence of stale prices and an implicit factor model extracted from a principal component analysis. For all models the mean alpha for large funds exceeds the mean alpha for small funds. The separation of the data in small and large funds is simplistic and not sufficient to measure the relationship between fund sizes and performance.

A similar approach has been chosen by Kazemi and Schneeweis [2003]. At the beginning of each year funds within each style are either assigned a large or a small subgroup depending on the size of assets under management. The authors find that large or small funds do not 
uniformly outperform the other group. The study contains only 15 to 30 hedge funds in each subgroup.

Getmansky [2004] analyses the effects of fund and strategy specific factors on life cycles of hedge funds and confirms that better performing funds are more likely to attract assets than poorly performing funds. The performance-asset size relationship takes on different functional forms for different strategies. For instance, for illiquid strategies such as "emerging markets" and "convertible arbitrage" the relationship is concave so that the top performing funds do not grow proportionally as much as the average fund in the market. The use of quadratic regressions raises the question of data fitting. The use of the relationship between fund sizes and the performance of individual strategies is limited to the relative low number of funds per strategy.

\section{DATA SET}

We combine three databases from TASS, one of today's largest commercial hedge fund data providers. Liang [2000, 2003] investigated the data quality of various hedge fund data providers and concluded that the TASS database has a high data quality in comparison to other commercial database providers. Many empirical studies are based on the TASS database. TASS maintains three separate databases, a hedge fund database with "living" hedge funds, one "graveyard" database with funds that stopped reporting and one CTA database. The combination of the three databases containing "living" and "dead" funds allows us to derive the survivorship bias. ${ }^{1}$ TASS started to build their databases in 1993/1994. The data prior to 1994 has been backfilled by hedge fund managers starting to report in 1994 or later. Therefore data prior to 1994 contains a number of biases and has not been used for our analysis.

All three TASS databases combined contain a total of 4327 funds: 2367 funds in the hedge fund database, 1542 funds in the graveyard database and 418 funds in the CTA database. From our data sample we eliminate 265 funds due to poor data quality or double counting. 707 of the remaining funds are classified as fund of hedge funds and have been excluded from the hedge fund data sample. For the remaining 3355 funds we have found the inconsistencies shown in Exhibit 1. Our findings confirm the concerns of other performance

\footnotetext{
${ }^{1}$ Survivorship bias occurs if the database only contains information on "surviving funds". Following Malkiel's method [1995], the bias is evaluated via the difference in the performance of the "observable" portfolio (investment in each fund in the database from the beginning of the data sample) and the portfolio of surviving funds.
} 
studies that asset data of hedge funds is very often incomplete. The inconsistencies in the asset development can partly be explained by the fact that some hedge funds have been reporting their assets only on a quarterly, semi-annual or annual basis, particularly in their early years of reporting.

On one hand we want to eliminate funds with incomplete data in order to avoid any additional biases in our data sample and on the other hand we do not want to lose too many funds for our analysis, since our sample would then be less representative for the Hedge Fund universe. We therefore need to find a compromise between data quality and data quantity. We decide to eliminate all funds with more than $10 \%$ missing data points in return data or more than $20 \%$ missing data points in asset data. The initial sample based on 3355 hedge funds is capturing assets of 241 billion USD in June 2003. With the adjustment we exclude 1027 funds with assets of 54 billion USD in June 2003. Missing data points in assets under management is the main restriction. Only 17 funds are not providing enough return data, while 1033 funds are providing less than $90 \%$ of the development of the assets under management. In addition to that the data is screened for extreme outliers exceeding $60 \%$ per month. If the extreme return data was not in line with the fund profile we conjectured a data error and eliminated the fund. We therefore excluded another eleven funds out of the sample due to a high likelihood of data errors in the return series. Finally we use a sample of 2317 funds with assets of 186 billion USD in June 2003. The data quality of the sample used in the performance study is illustrated in Exhibit 2.

\section{METHODOLOGY}

In order to analyze the impact of the fund size of hedge funds on the returns we use the following approaches.

In a first step we analyze the difference between asset-weighted and equally-weighted returns. We also investigate the difference in the survivorship bias using equally and asset weighted returns. Logarithmic data is used for the return analysis.

In a second step we use an asset class factor model to explain excess returns. ${ }^{2}$ We therefore define eleven asset class factors. The eleven asset class factors are the MSCI World,

\footnotetext{
${ }^{2}$ Schneeweis and Kazemi [2003] investigate three different methods to explain excess returns: (a) single-factor approach using a small capitalization equity index (b) a multi-factor linear unconditional model and (c) a $\mathrm{SDF} / \mathrm{GMM}$ approach. The authors find that in most cases the alphas are rather similar regardless of the empirical methodology applied.
} 
the NASDAQ Composite Index, the Russell 2000 Index, the Wilshire Micro Cap Index, the Lehman Aggregate Bond Index, the Lehman High Yield Credit Bond Index, the JP Morgan Government Bond Index, the Goldman Sachs Commodity Index, the IPE Brent Crude Oil Index, the London Gold Buillon USD Index, the 90-day T-Bill rate and the Chicago Board Options Exchange SPX Volatility Index. Our factor model is similar to the Sharpe's [1992] "style regression" with the difference that we distract the risk-free rate and therefore use the excess return as the dependent variable. The equation

$$
r_{t}-r_{f}=\text { Alpha }+\sum_{k=1}^{n} \beta_{k} x_{k t}+\varepsilon_{t}
$$

with $k$ factors and the factor loadings $\beta_{k}$ is used. We use the least square method in our regressions. We assume a factor structure for returns according to the arbitrage pricing theory. In order to facilitate the interpretations of the results we reduce the number of factors by using two different approaches. In our first approach we divide the eleven factors in four asset classes and test for the optimal factor of each asset class. In our second approach we use a stepwise regression. ${ }^{3}$ In both factor reduction approaches we derive to the same factor model used for further analysis.

In a third step we break the sample according to the fund sizes into 100 percentiles. The average fund size and the average returns are calculated for each percentile $i$. Monthly data is used to conduct the analysis. The natural logarithm of the average asset sizes and the natural logarithm of the quadratic average asset sizes are then regressed on the average annualized returns for the 100 percentiles. We therefore specify linear regressions of the form

$$
r_{i}=\alpha_{i}+\beta_{1} \log \left(\text { Assets }_{i}\right)+\varepsilon_{i}
$$

and quadratic regression of the form

$$
r_{i}=\alpha_{i}+\beta_{1} \log \left(\text { Assets }_{i}\right)+\beta_{2} \log \left(\text { Assets }_{i}\right)^{2}+\varepsilon_{i}
$$

Similarly we regress the fund sizes on annualized standard deviations and on annualized risk-adjusted returns using the following linear and quadratic specifications. The standard deviations and Sharpe Ratios are referring to percentiles and not to individual funds. Each percentile can be considered as a portfolio of funds with similar fund sizes.

\footnotetext{
${ }^{3}$ Stepwise regression has been used by other researchers including Liang [1999] and Agarwal [2001]. Please note that stepwise regression procedure can be used with different selection criteria. We consciously do not use maximizing the in-sample R-Squared as our selection criteria.
} 


$$
\begin{aligned}
& \sigma_{i}=\alpha_{i}+\beta_{1} \log \left(\text { Assets }_{i}\right)+\varepsilon_{i} \\
& \sigma_{i}=\alpha_{i}+\beta_{1} \log \left(\text { Assets }_{i}\right)+\beta_{2} \log \left(\text { Assets }_{i}\right)^{2}+\varepsilon_{i} \\
& S R_{i}=\alpha_{i}+\beta_{1} \log \left(\text { Assets }_{i}\right)+\varepsilon_{i} \\
& S R_{i}=\alpha_{i}+\beta_{1} \log \left(\text { Assets }_{i}\right)+\beta_{2} \log \left(\text { Assets }_{i}\right)^{2}+\varepsilon_{i}
\end{aligned}
$$

For the calculation of the Sharpe ratios we use 90-days T-Bill rates as risk free rate.

We also calculate the alphas for each individual percentile and therefore apply the model described in equation (1) 100 times to derive equation (8).

$$
r_{i t}-r_{f t}=A l p h a_{i}+\sum_{k=1}^{n} \beta_{i k} x_{i k t}+\varepsilon_{i t}
$$

We then test the relationship between the alphas derived from the 100 factor models and the average fund sizes for the 100 percentiles with the following linear and quadratic regressions.

$$
\begin{aligned}
& \text { Alpha }_{i}=\alpha_{i}+\beta_{1} \log \left(\text { Assets }_{i}\right)+\varepsilon_{i} \\
& \text { Alpha }_{i}=\alpha_{i}+\beta_{1} \log \left(\text { Assets }_{i}\right)+\beta_{2} \log \left(\text { Assets }_{i}\right)^{2}+\varepsilon_{i}
\end{aligned}
$$

\section{HEDGE FUND RETURNS}

In this section we conduct our empirical analysis with the data sample described before.

\section{Equally versus asset weighted returns}

Different from previous studies, we focus on the average returns achieved by hedge fund investors in contrast to the returns achieved by the average hedge fund. The difference lies in the measurement method of hedge fund returns. To our knowledge most existing studies about the performance of hedge funds are using equally weighted returns in order to estimate returns of the unobservable hedge fund universe. We use asset weighted returns of a large sample of hedge funds for performance measurement purposes. One reason why most studies have focused on equally weighted hedge fund returns is the poor data quality of hedge funds' assets under management. Since the quality of available data improved significantly in the last years, it is now feasible to calculate asset weighted returns. A number of index providers developed different methodologies to benchmark hedge fund returns. Most hedge fund indices 
are equally weighted with the exception of the CSFB-Tremont Hedge Fund Indices ${ }^{4}$ and some of the recently launched MSCI Hedge Fund Indices.

We calculate both, equally weighted and asset weighted returns for our data sample based on the TASS databases for various time periods from January 1994 to June 2003. The results can be found in Exhibit 3. Our results are not subject to the survivorship bias, since both "dead" and "living" funds are included in the analysis. The instant history bias and the selection bias are hard to avoid and are therefore affecting the results. We calculate the survivorship bias of the TASS hedge fund database in the following subsection.

The annualized return differences between equally and asset weighted returns is $0.95 \%$ over the 9.5 years time horizon. Interestingly the difference is positive in the time period from January 1994 to June 1998, but negative from July 1998 to June 2003. The differences are not statistically significant at the 5\% significance level.

Exhibit 4 shows a comparison between the rolling 12-months equally weighted and the rolling 12-months asset weighted returns. We can observe temporary differences between equally and asset weighted returns in the late 90s. This phenomenon can be explained by the fact that very few large hedge funds were dominating the returns of the hedge fund industry at that time drawing the asset weighted returns up in 1997 and 1998, but causing an underperformance in 1999.

\section{Differences in the survivorship bias}

We also investigate whether smaller funds have a larger survivorship bias than larger funds. The results are illustrated in Exhibit 5. The annualized differences between the survivorship bias calculated with equally weighted returns and the survivorship bias calculated with asset weighted returns is significant at the 5\% significance level for the 9.5year period as well as for the first sub period from January 1994 to June 1998. We can therefore state that small firms face an increased risk of exiting the database.

If we are willing to believe that asset weighted returns are more representative for the hedge fund industry then we need to be careful in interpreting the results of many existing studies based on equally weighted returns. Our findings based on asset weighted returns are useful from a macro perspective and relevant to measure the survivorship bias of the hedge

\footnotetext{
${ }^{4}$ The CSFB-Tremont Hedge Fund Indices contain approximately 400 Hedge Funds and represents 160 billion USD in assets. The index clearly focuses on large Hedge Funds. Hedge Funds require a minimum of 10 million USD assets under management, a minimum track record of one year and audited financial statements in order to become part of the index.
} 
fund industry in general. If we want to interpret the results from the perspective of the individual hedge fund investor who is equally distributing his investments to a number of hedge funds regardless of the hedge fund size, then the survivorship bias derived from equally weighted returns is the more accurate measure.

Exhibit 6 illustrates the development of the survivorship bias in equally and asset weighted returns over time. Using 12-months rolling return data we can see that the survivorship bias with asset weighted returns is less stable. Particularly in the period around 1998 the rolling survivorship bias with asset weighted returns is deviating significantly from the long term average.

We are aware that funds may voluntarily stop reporting because they do not want to publish bad performance and harm their reputation. We cannot assume that funds dropping from the database are really ceasing their operation. TASS classifies to some extent exiting funds in seven categories. A summary can be found in Exhibit 7. 51\% of the exiting funds have been liquidated and $3.5 \%$ of the funds merged with other funds. Other reasons for exiting are more difficult to interpret. Only six funds indicated that they closed for new investments, but the number might be much higher, since more than $45 \%$ of the funds refused to state any reason for exiting or were unreachable.

\section{Factor Model}

We want to explain excess returns of hedge funds with an asset class factor model in order to derive hedge fund alphas. Exhibit 8 represents the results of a multiple regression of the eleven asset class factors on the returns of our sample with 2317 funds. Almost $54 \%$ of the excess returns can be explained with the eleven-factor asset-class model. The Goldman Sachs Commodity Index, the Lehman Aggregate Bond Index and the Wilshire Micro Cap Index are the only three factors that are statistically significant at the $5 \%$ significance level. It is interesting to see that other equity indices including large cap and mid cap stocks are less useful to explain excess returns of hedge funds. This is an indication that hedge funds tend to focus on small cap stocks that have typically less research coverage from investment banks.

We therefore reduce the number of factor in order to better interpret the result. In our first factor reduction approach we start with a stepwise regression. The highest adjusted R-squared can be found in a factor model with seven factors represented in Exhibit 9. The Akaike info criterion is minimized in a model with four factors including the same factors as in Exhibit 9 with the exception of the MSCI World, the JPM Government Bond Index and crude oil. We 
continue eliminating factors until all remaining factors are significant at the 5\% significance level. We then find three factors that are significant. The Wilshire Micro Cap index and the Lehman Aggregate Bond index are significant at the 1\% significance level. The Goldman Sachs Commodity index is significant at the 5\% significance level. The results are presented in Exhibit 10. The constant, indicating the alpha of hedge funds, is positive, but not statistically significant. The annualized alpha of the model is $0.81 \%$. The asset class factor model with three factors is explaining more than $50 \%$ of the returns. The adjusted R-squared of the three factor model is above the adjusted R-squared of the factor model with eleven factors. As indicated in the eleven factor model, commodities, bonds and small-cap stocks are the most common risk-exposures of hedge funds.

In our second approach we start with single factor models for each asset class factor illustrated in Exhibit 11. We then take for each of the four asset classes the factor with the highest explanatory power and combine them in a factor model with four asset class factors. We then test for each asset class other potential factors with the objective to find a model with a higher adjusted R-Squared. An overview is given in Exhibit 12. We finally conclude that volatility as an asset class represented by the Chicago Board Options Exchange SPX Volatility Index is not significantly increasing the adjusted R-Squared of the model and is therefore excluded. We are therefore left with the same three asset class factors as in the first factor reduction approach representing commodities, equities and currencies.

We further explore the relevance of the three factors chosen in our three factor asset class model. We break the sample data into 100 percentiles according to their fund sizes and conduct a principal component analysis on the 100 time series representing the average returns of each percentile. The result of the principal component analysis is presented in Exhibit 13 . The first component explains $40.84 \%$ of the variance and the first ten components together explain $61.53 \%$ of the variance. The cumulative variance explained of the first three components is $47.60 \%$ and therefore lower than the variance explained by the asset class factor model with three factors shown in Exhibit 10. The scree plot of the principal component analysis presented in Exhibit 14 illustrates the dominance of the first component versus the other components based on the Eigenvalues.

\section{Cross-sectional regressions}


In this sub-section we use cross-sectional regressions to identify the impact of fund sizes on excess, returns, standard deviations, Sharpe Ratios and alphas. We use the breakdown of the sample data into 100 percentiles based on their fund sizes. Each percentile can be regarded as a sub-sample. The constitution of the sub-samples changes in each month as the assets under management are changing and funds with increasing assets relative to its peer group fall into a higher percentile. In our first regression we regress the logarithm of the average fund sizes of the 100 sub-samples on the average excess returns of the sub-samples.

Exhibit 15 shows the deciles of fund sizes and the annualized average returns of the hedge funds in each decile. We can see that very small funds of the bottom decile are underperforming. This phenomenon can be explained by an economy of scale effect. The operational expenses play a significant role for smaller funds and make it uneconomic to run a fund with a very small asset base. Funds from the $21^{\text {st }}$ to the $50^{\text {th }}$ percentile have the best performance. At this stage hedge funds are still relatively small with an asset base of less than 20 million USD. Many institutional investors are focussing on hedge funds with a larger asset base and are therefore eliminating funds with the highest return potential based on the indication of asset sizes. An institutional investor who is looking for funds with a minimum of 50 million USD under management will only focus on funds in the top three deciles. We know that many of the largest funds are closed for investment and many investors are therefore left with a relatively small universe of a few hundred hedge funds. Funds from the $51^{\text {st }}$ to the $100^{\text {th }}$ percentile tend to have similar average returns. This result suggests that it would not make a large difference of picking a hedge fund with 30 million USD assets or a multi-billion USD hedge fund.

We further investigate the relationship between fund sizes and returns. Therefore we apply a simple regression analysis of the logarithm of the fund sizes on the average returns of the asset percentiles. The results of the linear regression analysis are presented in Exhibit 16 and Exhibit 17. Each data point in Exhibit 16 represents an average annualized return for one asset percentile in our data sample. The linear relationship between returns and fund sizes is statistically significant at the $1 \%$ significance level.

Investigating the scatter plot in Exhibit 16 we conjecture a non-linear relationship between fund-sizes and returns. Applying a quadratic regression analysis we can find a concave relationship that basically confirms the finding of Getmansky [2004]. The curve in Exhibit 16 represents the results of the quadratic regression. The quadratic term in the regression analysis is significant at the $1 \%$ significance level. 
We can see that particularly very small funds with less than 1'000'000 USD in assets under management are very often underperforming. The underperformance can be explained by higher relative operational costs. Minimum fixed costs for the management of the hedge fund vehicle, fund administration and custody are the major operational costs that are diminishing net returns for the investor. It is difficult to derive the impact of fund sizes on gross returns, since the total expense ratio of individual hedge funds is generally not reported.

We also explore the impact of fund sizes on volatilities in a linear and quadratic regression analysis. The volatilities refer to percentiles and therefore portfolios of hedge funds, rather than individual hedge funds. The volatility of portfolios of hedge funds is generally lower than the volatility of individual hedge funds due to diversification effects.

The linear regression indicates a significant relationship at the 5\% significance level. We also test the relationship for convexity and find that the quadratic term in the quadratic regression is not statistically significant at the 5\% significance level. The results can be found in Exhibit 18 and Exhibit 19.

The relationship between fund sizes and standard deviations is intuitive since large funds generally benefit from a broader diversification and therefore a reduction of volatilities. Larger funds very often attracted assets based on a proven track record and might therefore shift their focus on capital preservation. Highly aggressive strategies with concentrated bets are sometimes more difficult to implement with a large asset base due to capacity constraints.

Larger funds are very often in a position to better control the asset flows and therefore benefit from a more stable income. To control the asset flows larger funds can more easily afford less favourable liquidity conditions for investors and keep investors in the fund by applying lockup periods, maximum redemption gates or redemption fees for early withdrawal of investments. A stable asset base allows for better planning of investments. The manager can therefore more consistently apply his strategy or also invest in illiquid securities that are not priced on a daily basis and therefore diminish the volatility of the fund.

Next, we explore the relationship between asset sizes and Sharpe Ratios with a linear and a quadratic regression approach. Similar to the standard deviations, the Sharpe Ratios are referring to asset percentiles that are representing portfolios of hedge funds with similar size. Due to the diversification effect of portfolios the Sharpe Ratios of individual hedge funds are typically lower than the Sharpe Ratios of portfolios. The findings of our regression analysis are illustrated in Exhibit 20 and Exhibit 21. In the linear regression the relationship between fund sizes and Sharpe Ratios is significant at the $1 \%$ significance level. In the quadratic 
regression the quadratic term is significant at the 5\% significance level. Using the results of the quadratic regression it is therefore generally possible to find an optimal asset size with the highest Sharpe Ratio, although the quadratic relationship is not necessarily obvious from the scatter plot. Additionally, as can be seen from Exhibit 20, nonlinearity tends to be driven by very small funds. Thus, it cannot be concluded that very large hedge funds have lower Sharpe Ratios than medium-sized funds.

In the next step we are exploring the relationship between fund sizes and the alphas derived from our asset class factor model with three factors. We are using the three factors that have the highest explanatory power given the eleven initial factors. We remember that the alphas in our 3-factor model account for risk exposures to commodities, small-cap stocks and bonds. Exhibit 22 and Exhibit 23 illustrate the results of our regression analysis. The coefficient of our linear regression is significant at the $1 \%$ significance level and indicates higher alphas for larger hedge funds. The coefficients of the quadratic regression are significant and therefore indicate a concave relationship between fund sizes and alphas.

We investigate if the Wilshire Micro Cap Index as a factor in the 3-factor model is benefiting small hedge funds. Based on the conjecture that smaller funds may have a different investment focus and more exposure to a small-cap index we replace the Wilshire Micro Cap Index in our 3-factor model with the MSCI World and then apply the same cross-sectional regression between asset percentiles and the new alphas. We find that the linear relationship between fund sizes and the alphas from the adjusted factor model is even stronger. The results are displayed in Exhibit 24. We therefore have to reject this conjecture and confirm the robustness of the results based on our original 3-factor model.

We also test whether large hedge funds have more interest rate exposure since fixed income related hedge funds typically have a larger asset base due to the nature of their strategy. We therefore drop the Lehman Aggregate Bond Index as an explanatory factor in our 3 -factor model and derive the alphas from an adjusted 2-factor model based on the Goldman Sachs Commodities Index and the Wilshire Micro Cap Index. Our results illustrated in Exhibit 25 indicate a weaker relationship between fund sizes and alphas that is still significant at the $5 \%$ significance level.

It remains difficult to estimate whether large funds are taking more exposure to risk factors that are not captured by the simple asset class factor model compared to small funds. In any case the higher relative expense ratio of smaller funds is decreasing the alphas based on net returns. For very small funds the alpha is even negative. 
Based on the parameters found in our quadratic regression analysis we can derive optimal asset sizes. However, we generally conclude that the convex and concave relationships are weak and the usefulness of the quadratic regressions is therefore limited.

\section{CONCLUSION}

This article contributes to existing literature about hedge funds performance with a detailed analysis of the impact of fund sizes on returns, Sharpe Ratios and alphas derived from a multi asset class factor model. Based on a large sample of hedge fund returns we reveal empirical evidence for a positive relationship between fund sizes and returns using cross sectional regression techniques. We find that particularly very small funds are underperforming on average. We conjecture that the underperformance is based on higher total expense ratios of small funds. On the other side the observed relationship between standard deviations and fund assets is negative. Generally larger funds tend to have lower volatilities, but higher Sharpe Ratios. Very small funds have a clear disadvantage to compete with medium- and larger-sized funds.

We show that the average alphas generated by hedge funds derived from a simple asset class factor model are not statistically significant in the long term. It is interesting to see that the positive relationship between fund sizes and returns also holds after adjusting the returns for the risk free rate and factor exposures to commodities, small-cap stocks and bonds. Similar than our analysis based on annualized returns and Sharpe Ratios, our analysis based on alphas reveals that very small funds are underperforming on average.

Hedge fund managers are primarily remunerated with a performance fee. In absolute terms the performance fee can be increased by higher returns, but also by a larger asset base. A hedge fund manager who is maximizing his income may therefore be willing to grow a fund above its optimal size from a pure performance perspective. In the long-term a good performance is instrumental in attracting assets and also enhances the reputation of the manager. Therefore the manager faces a trade-off between optimizing the performance of the fund and optimizing his revenues. Nevertheless, in this study, the empirical evidence for managers increasing their fund size beyond the optimal point is very weak. The number of large funds exceeding 100 million USD assets under management is very small compared to the total number of hedge funds.

Different hedge fund strategies have different capacity limits. The strategy-specific characteristics of the asset-return relationship open opportunities for further research projects. 
For our percentiles based approach, however, the number of hedge funds available for each hedge fund strategy is not sufficient to break the strategy-specific samples further down into 100 sub-samples over a 9.5 year period. The results of strategy-specific analysis are therefore limited by the data available. 


\section{REFERENCES}

Agarwal, V., and N. Naik, "Performance Evaluation of Hedge Funds with option-based and Buy-and-Hold Strategies", Working Paper, London Business School, 2000.

Agarwal, V., and N. Naik, "Characterizing Hedge Fund Strategies with Buy-and-Hold and Option-Based Strategies”, Working Paper, London Business School, 2001

Agarwal, N., and N. Naik, "Risks and Portfolio Decisions involving Hedge Funds", Working Paper, London Business School, 2003.

Amenc, M., Curtis, S., and L. Martellini, "The Alpha and Omega of Hedge Fund Performance”, Working Paper, Edhec/USC, 2003.

Brealey, R. A., and E. Kaplanis, "Changes in Factor Exposures of Hedge Funds", Working Paper, 2001.

Clark, A., "Does Fund Size Affect Performance?", Lipper Research Study, 2003.

Fama, E. F., and K. R. French, "Common Risk Factors in the Returns on Stocks and Bonds", Journal of Financial Economics (1993), pp3-56.

Fama, E. F., and K. R. French, "Multi-factor Explanations of Asset Pricing Anomalies", Journal of Finance (1996), pp131-155.

Fung, W., and D. Hsieh, "Empirical Characteristics of Dynamic Trading Strategies: The Case of Hedge Funds", The Review of Financial Studies (1997), pp275-302.

Getmansky, M., "The Life Cycle of Hedge Funds: Fund Flows, Size and Performance", Working Paper MIT, 2004.

Goetzmann, W., Ingersoll, J., and S. Ross, "High Water Marks and Hedge Fund Management Contracts", Journal of Finance (2003), pp1685-1717.

Gregoriou, G. N., and F. Rouah, "Large versus Small Hedge Funds: Does Size Affect Performance?”, Journal of Alternative Investments (2003), pp75-77.

Hedges, R. J., "Size vs. performance in the hedge fund industry", Journal of financial transformation, The capco institute, 2003.

Herzberg M. M., and H. A. Mozes, "The Persistence of Hedge Fund Risk: Evidence and Implications for Investors", Journal of Alternative Investments (2003), pp22-42.

Edwards, F. R., and M. Caglayan, "Hedge Fund Performance and Manager Skill”, Journal of Futures Markets (2001), pp1003-1028.

Kazemi, H., and Schneeweis, "Conditional Performance of Hedge Funds", Isenberg School of Management, University of Massachusetts, 2003.

Liang, B., "On the Performance of Hedge Funds", Financial Analysts Journal (1999), pp7285. 
Liang, B., "Hedge Funds: The Living and the Dead", Journal of Financial and Quantitative Analysis (2000), pp309-325.

Liang, B., "The Accuracy of Hedge Fund Returns", The Journal of Portfolio Management (2003), pp111-122.

Malkiel, B., "Returns from Investing in Equity Mutual Funds 1971 to 1991", Journal of Finance (1995), pp549-572.

Sharpe, W. F., “Asset Allocation: Management Style and Performance Measurement", The Journal of Portfolio Management (1992), pp7-19.

Schneeweis, T., Kazemi H., and G. Martin, "Understanding Hedge Fund Performance: Research Issues Revisited - Part II", The Journal of Alternative Investments (2003), pp8-30. 


\section{EXHIBIT 1}

\section{Data quality in the TASS database}

\begin{tabular}{lcc}
\hline Missing Returns & in Funds & in $\%$ \\
\hline More than 1 datapoint & 126 & $3.71 \%$ \\
More than 5\% & 76 & $2.24 \%$ \\
More than 10\% & 17 & $0.50 \%$ \\
More than 20\% & 5 & $0.15 \%$ \\
More than 30\% & 2 & $0.06 \%$ \\
\hline More than 40\% & 0 & $0.00 \%$ \\
\hline & & \\
\hline Missing Assets & in Funds & in \\
\hline More than 1 missing datapoint & 1407 & $41.47 \%$ \\
More than 10\% & 1033 & $30.45 \%$ \\
More than 30\% & 586 & $18.39 \%$ \\
More than 50\% & 394 & $11.61 \%$ \\
\hline
\end{tabular}

A large number of funds have missing data points in their development of assets under management. The data quality is higher for return data. The data source is the TASS database. 


\section{EXHIBIT 2}

\section{Data quality of our data sample with 2317 funds}

\begin{tabular}{lcc}
\hline Missing Returns & in Funds & in $\%$ \\
\hline Funds with at least 1 missing return & 300 & $12.95 \%$ \\
More than 1 missing datapoint & 61 & $2.63 \%$ \\
More than 1\% & 247 & $10.66 \%$ \\
More than 3\% & 99 & $4.27 \%$ \\
More than 5\% & 35 & $1.51 \%$ \\
\hline More than 10\% & 0 & $0.00 \%$ \\
\hline & & in \% \\
\hline Missing Assets & in Funds & $29.42 \%$ \\
At least 1 datapoint & 679 & $16.32 \%$ \\
More than 1 missing datapoint & 375 & $11.52 \%$ \\
More than 5\% & 267 & $0.30 \%$ \\
More than 10\% & 7 & $0.00 \%$ \\
\hline More than 20\% & 0 & 1 \\
\hline
\end{tabular}

This exhibit describes the quality of the data set used in the empirical part of our study. The data source is the TASS database. 2317 hedge funds are used for the empirical analysis. 


\section{EXHIBIT 3}

\section{Return comparison based on a sample with 2317 hedge funds}

\begin{tabular}{lccc}
\hline & Jan 94 - Jun 03 & Jan 94 - Jun 98 & Jul 98 - Jun 03 \\
\hline Equally weighted returns p.a. & $9.88 \%$ & $11.32 \%$ & $8.59 \%$ \\
Standard Deviation p.a. & $5.78 \%$ & $5.81 \%$ & $5.78 \%$ \\
Sharpe Ratio & 0.97 & 1.21 & 0.74 \\
& & & \\
Asset weighted returns p.a. & $10.83 \%$ & $14.08 \%$ & $7.92 \%$ \\
Standard Deviation p.a. & $5.73 \%$ & $6.24 \%$ & $5.13 \%$ \\
Sharpe Ratio & 1.14 & 1.57 & 0.71 \\
& & & \\
Annualized differences in returns & $0.95 \%$ & $2.76 \%$ & $-0.67 \%$ \\
Standard Deviation p.a. & $3.24 \%$ & $3.44 \%$ & $3.00 \%$ \\
t-Statistic & 0.91 & 1.70 & -0.50 \\
\hline
\end{tabular}

Equally weighted and asset weighted returns are calculated for a 9.5 years time horizon and for two sub-periods from January 1994 to June 1998 and from July 1998 to June 2003. The significance of the return differences is tested with a t-Statistic. 


\section{EXHIBIT 4}

Equally versus asset weighted logarithmic returns

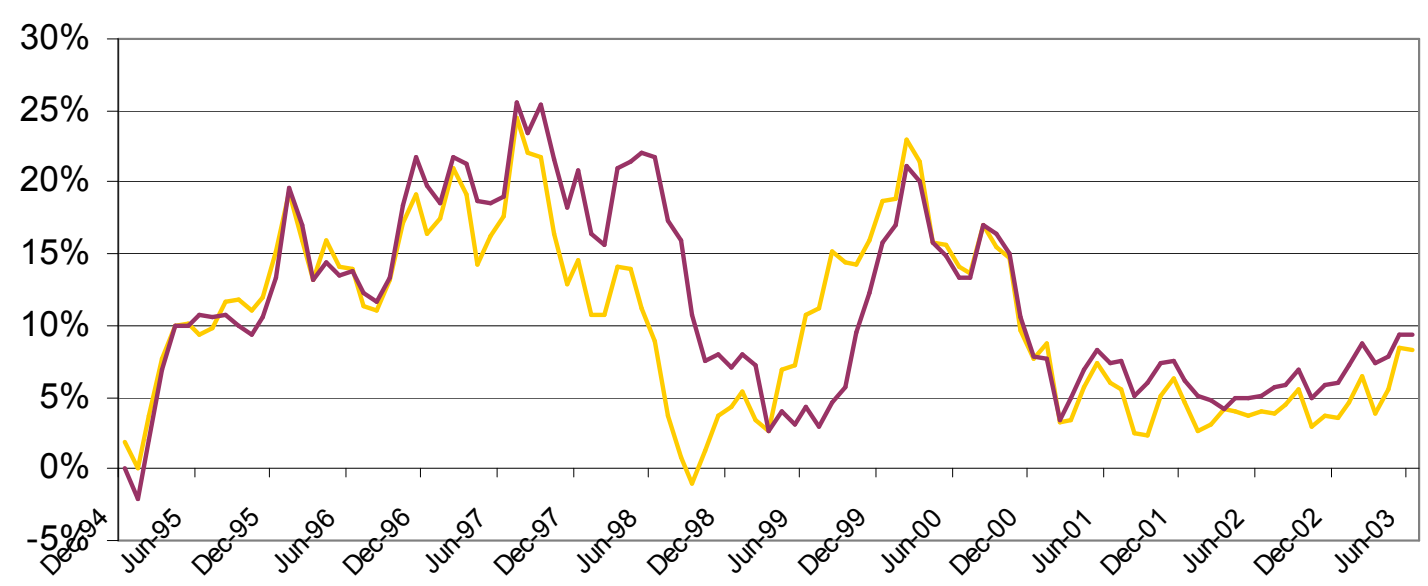

_ Rolling 12 months equally weighted returns

— Rolling 12 months asset weighted returns 


\section{EXHIBIT 5}

\section{Survivorship Bias based on a sample with 2317 hedge funds}

\begin{tabular}{lccc}
\hline & Jan $94-$ Jun 03 & Jan $94-$ Jun 98 & Jul 98 - Jun 03 \\
\hline Surv. Bias with equally weighted return & $2.44 \%$ & $2.72 \%$ & $2.20 \%$ \\
Surv. Bias with asset weighted returns & $0.85 \%$ & $-1.33 \%$ & $2.82 \%$ \\
& & & \\
Differences in Survivorship Bias p.a. & $1.59 \%$ & $4.05 \%$ & $-0.62 \%$ \\
Standard Deviation p.a. & $2.35 \%$ & $2.58 \%$ & $1.94 \%$ \\
t-Statistic & 2.09 & 3.33 & -0.72 \\
\hline
\end{tabular}

The survivorship biases of equally weighted and asset weighted returns are calculated for a 9.5 years time horizon and for two sub-periods from January 1994 to June 1998 and from July 1998 to June 2003. The significance of the differences in the survivorship biases are tested with a t-Statistic. 


\section{EXHIBIT 6}

\section{2-months rolling survivorship biases}

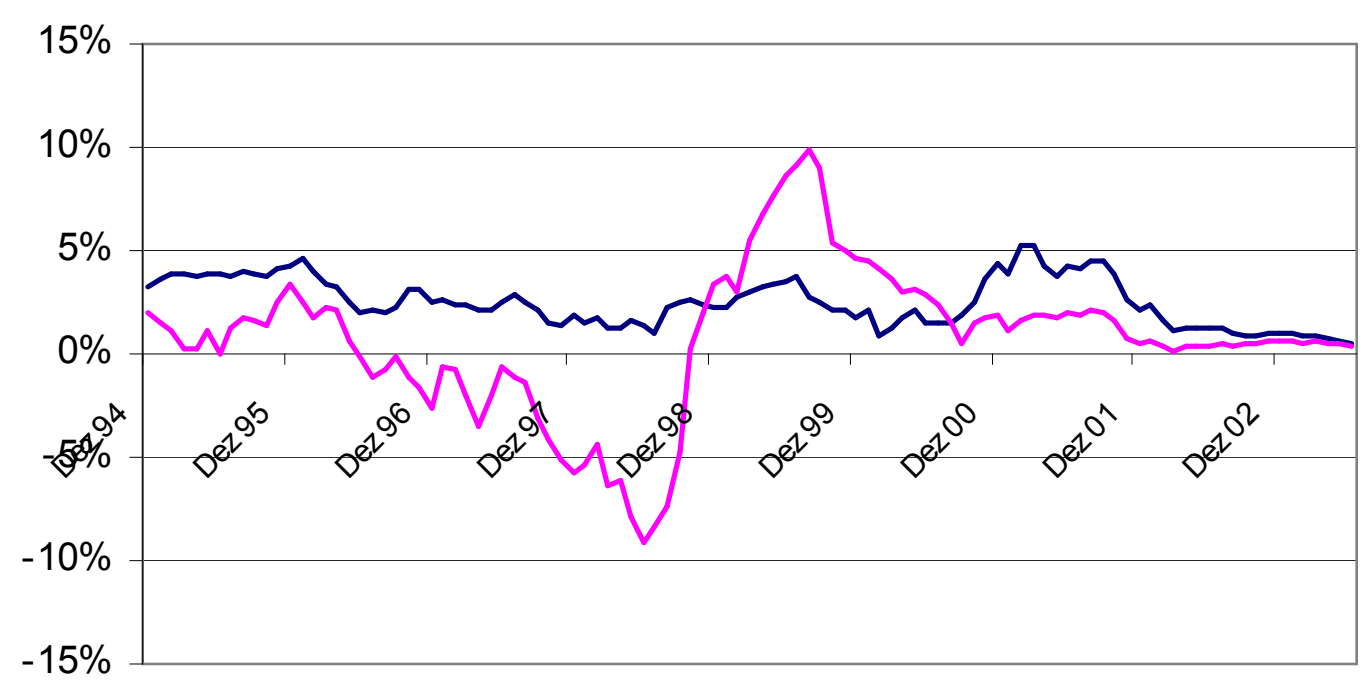

_ Rolling equally weighted survivorship bias

__ Rolling asset weighted survivorship bias 


\section{EXHIBIT 7}

\section{TASS Graveyard database - reasons for exiting}

\begin{tabular}{ll}
\hline Funds liquidated & 800
\end{tabular}

Funds no longer reporting to TASS $\quad 438$

TASS has been unable to contact the manger for updated information 146

$\begin{array}{lr}\text { Funds closed to new investment } & 6\end{array}$

Funds merged into another entity $\quad 56$

Funds dormant 2

\begin{tabular}{lr} 
Unknown & 134 \\
\hline AllFunds & 1582
\end{tabular}

\begin{tabular}{lr}
\hline All Funds & 1582 \\
\hline
\end{tabular}

The hedge funds in the TASS Graveyard database are classified according to their reasons for exiting. The exhibit illustrates the classification taking data until June 2003 into account. 
EXHIBIT 8

Asset class factor model with eleven factors

\begin{tabular}{lcccc}
\hline Variable & Coefficient & Std. Error & t-Statistic & Prob. \\
\hline ALPHA & 0.0010 & 0.0014 & 0.7248 & 0.4703 \\
VIX & 0.0003 & 0.0082 & 0.0374 & 0.9702 \\
GOLD & 0.0294 & 0.0353 & 0.8333 & 0.4066 \\
GSCI & 0.0761 & 0.0317 & 2.3965 & 0.0184 \\
JPM GOV BOND & -0.1040 & 0.0905 & -1.1499 & 0.2529 \\
LEHM BOND & 0.3251 & 0.1347 & 2.4143 & 0.0175 \\
LEHMAN HY & 0.0043 & 0.0678 & 0.0640 & 0.9491 \\
MSCI WORLD & 0.0301 & 0.0279 & 1.0787 & 0.2833 \\
NASDAQ & 0.0283 & 0.0259 & 1.0919 & 0.2775 \\
CRUDE OIL & -0.0180 & 0.0185 & -0.9751 & 0.3318 \\
RUSSEL 2000 & 0.0323 & 0.0561 & 0.5764 & 0.5656 \\
WILSHIREMICRO & 0.0909 & 0.0413 & 2.2026 & 0.0299 \\
\hline R-squared & 0.5370 & Adjusted R-squared & 0.4871 \\
\hline
\end{tabular}

A multi asset class factor model with eleven factors is used to explain excess returns of hedge funds. Standard errors and t-Statistics as well as p-probabilities are calculated for each factor. 


\section{EXHIBIT 9}

\section{Asset class factor model with seven factors}

\begin{tabular}{lcccc}
\hline Variable & Coefficient & Std. Error & t-Statistic & Prob. \\
\hline ALPHA & 0.0008 & 0.0013 & 0.6330 & 0.5281 \\
GSCI & 0.0804 & 0.0304 & 2.6402 & 0.0095 \\
JPM GOV BOND & -0.0851 & 0.0804 & -1.0583 & 0.2923 \\
LEHM BOND & 0.3164 & 0.1233 & 2.5662 & 0.0117 \\
MSCI WORLD & 0.0341 & 0.0244 & 1.3959 & 0.1657 \\
NASDAQ & 0.0308 & 0.0229 & 1.3457 & 0.1813 \\
CRUDE OIL & -0.0186 & 0.0178 & -1.0473 & 0.2974 \\
WILSHIRE MICRO & 0.1140 & 0.0275 & 4.1413 & 0.0001 \\
\hline R-squared & 0.5316 & Adjusted R-squared & 0.5007 \\
\hline
\end{tabular}

A multi asset class factor model with seven factors is used to explain excess returns of hedge funds. Standard errors and t-Statistics as well as p-probabilities are calculated for each factor. 
EXHIBIT 10

Asset class factor model with three factors

\begin{tabular}{lcccc}
\hline Variable & Coefficient & Std. Error & t-Statistic & Prob. \\
\hline ALPHA & 0.0007 & 0.0013 & 0.5258 & 0.6001 \\
GSCI & 0.0491 & 0.0198 & 2.4848 & 0.0145 \\
LEHM BOND & 0.2713 & 0.1034 & 2.6229 & 0.0100 \\
WILSHIRE MICRO & 0.1529 & 0.0162 & 9.4340 & 0.0000 \\
& & & & 0.4897 \\
\hline
\end{tabular}

A multi asset class factor model with three factors is used to explain excess hedge fund returns. Standard errors and t-statistics as well as p-probabilities are calculated for each factor. 


\section{EXHIBIT 11}

Single Factor Models for eleven asset class factors

\begin{tabular}{lllc}
\hline ASSET CLASSES & \multicolumn{1}{c}{ FACTORS } & MONTHLY ALPHA & $\begin{array}{c}\text { ADJUSTED R- } \\
\text { SQUARED }\end{array}$ \\
\hline EQUITIES & WILSHIRE MICRO & $0.26 \%$ & 0.4308 \\
& MSCI WORLD & $0.41 \%$ & 0.0549 \\
& NASDAQ & $0.35 \%$ & 0.3545 \\
& RUSSELL 2000 & $0.32 \%$ & 0.4213 \\
\hline BONDS & LEHMAN HY & $0.29 \%$ & 0.1767 \\
& LEHM BOND & $0.30 \%$ & 0.0250 \\
& JPM GOV BOND & $0.44 \%$ & -0.0070 \\
\hline COMMODITIES & GOLD & $0.47 \%$ & 0.0116 \\
& GSCI & $0.41 \%$ & 0.0704 \\
& OIL & $0.44 \%$ & 0.0130 \\
\hline VOLATILITY & VIX & $0.54 \%$ & 0.1492 \\
\hline
\end{tabular}

A single asset class factor model for all eleven asset class factors is used to explain excess returns of hedge funds. Monthly alphas and adjusted R-Squares are calculated for each model. 
EXHIBIT 12

R-Squares of factor models based on four asset classes

\begin{tabular}{lcccc}
\hline EQUITIES & BONDS & COMMODITIES & VOLATILITY & $\begin{array}{c}\text { ADJUSTED } \\
\text { R-SQARED }\end{array}$ \\
\hline WILSHIRE MICRO & LEHMAN HY & GOLD & VIX & 0.4332 \\
MSCI WORLD & LEHMAN HY & GOLD & VIX & 0.2389 \\
NASDAQ & LEHMAN HY & GOLD & VIX & 0.3809 \\
RUSSELL 2000 & LEHMAN HY & GOLD & VIX & 0.4169 \\
\hline WILSHIRE MICRO & LEHM BOND & GOLD & VIX & 0.4652 \\
WILSHIRE MICRO & JPM GOV BOND & GOLD & VIX & 0.4371 \\
\hline WILSHIRE MICRO & LEHM BOND & GSCI & VIX & 0.4918 \\
WILSHIRE MICRO & LEHM BOND & OIL & VIX & 0.4692 \\
\hline WILSHIRE MICRO & LEHM BOND & GSCI & & 0.4897 \\
\hline
\end{tabular}

A multi asset class factor model with four factors, one of each asset class is used to explain excess hedge fund returns. The initial asset class factors are derived from the highest adjusted R-Squares within each asset class from the single factor models. For each asset class all asset class factors are tested given the asset class factors of the other asset classes. Adjusted R-Squared are calculated for each model. 


\section{EXHIBIT 13}

\section{Principal Component Analysis}

\begin{tabular}{ccc}
\hline Component & \% of Variance Explained & Cumulative \% of Variance Explained \\
\hline 1 & 40.84 & 40.84 \\
2 & 3.81 & 44.64 \\
3 & 2.96 & 47.60 \\
4 & 2.57 & 50.17 \\
5 & 2.21 & 52.37 \\
6 & 1.99 & 54.37 \\
7 & 1.94 & 56.31 \\
8 & 1.85 & 58.16 \\
9 & 1.72 & 59.87 \\
10 & 1.65 & 61.53 \\
\hline
\end{tabular}

The funds are ranked according to their fund sizes and 100 asset percentiles are built in each month. The principal component analysis is based on the returns of the 100 percentiles. The first component explains $40.84 \%$ of the variance and the first ten components explain $61.53 \%$ of the variance. 


\section{EXHIBIT 14}

\section{Scree Plot of Principal Component Analysis}

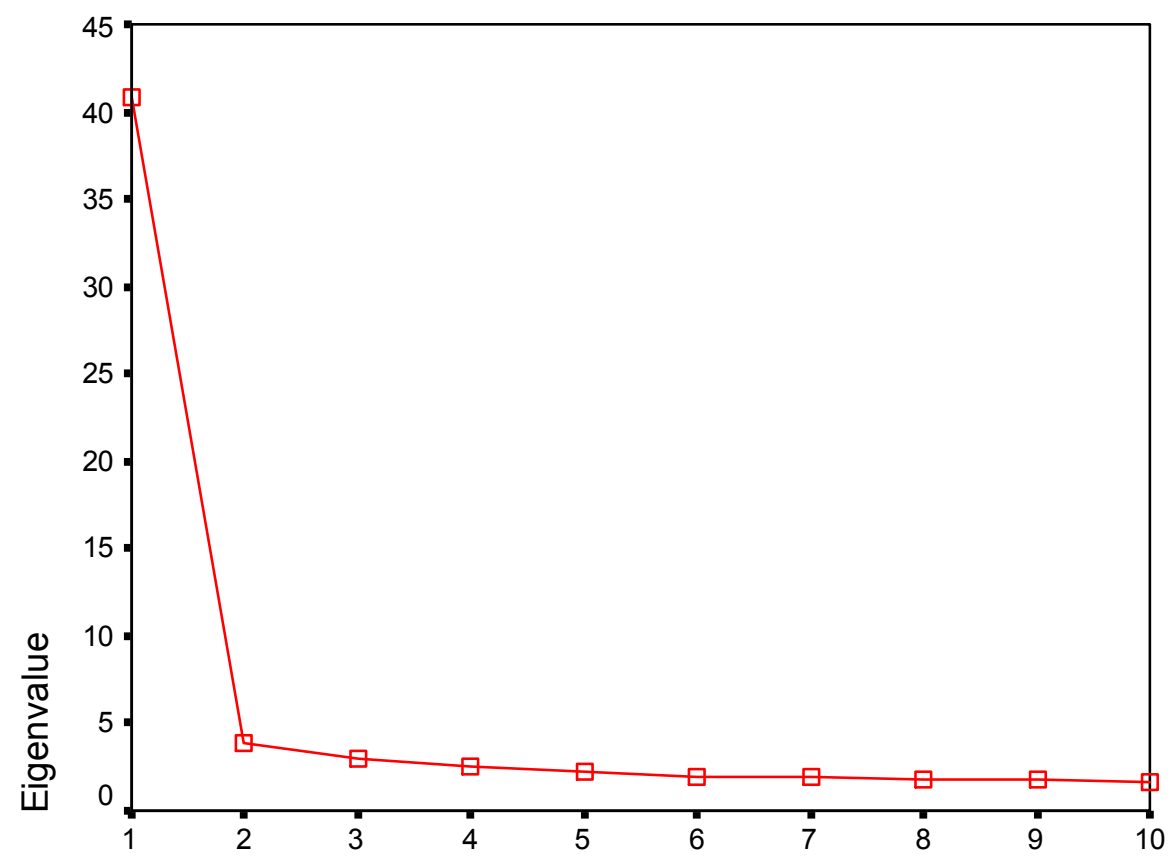

Component Number

The scree plot of the principal component analysis illustrates the variance explained by each of the first ten components. 


\section{EXHIBIT 15}

\section{Hedge fund assets and returns}

\begin{tabular}{ccc}
\hline Percentile & Average Assets & Average Returns \\
\hline 91st - 100th & $535^{\prime} 395^{\prime} 919$ & $10.71 \%$ \\
81st - 90th & $124^{\prime} 524^{\prime} 928$ & $9.99 \%$ \\
71st - 80th & $65^{\prime} 117^{\prime} 225$ & $9.92 \%$ \\
61st - 70th & $37^{\prime} 614^{\prime} 482$ & $11.02 \%$ \\
51st - 60th & $22^{\prime} 934^{\prime} 438$ & $9.89 \%$ \\
41st - 50th & $14^{\prime} 230 ' 139$ & $11.34 \%$ \\
31st - 40th & $8^{\prime} 567^{\prime} 511$ & $11.46 \%$ \\
21st - 30th & $4^{\prime} 832$ ' 842 & $11.53 \%$ \\
11th - 20th & $2{ }^{\prime} 348 ' 872$ & $9.66 \%$ \\
1st - 10th & $697^{\prime} 231$ & $7.05 \%$ \\
\hline
\end{tabular}

Our sample of 2317 hedge funds is classified in percentiles according to their fund sizes. The second column illustrates the average fund sizes of each decile. The third column shows the average returns for each decile. 


\section{Exhibit 16}

Log of asset sizes versus annualized returns

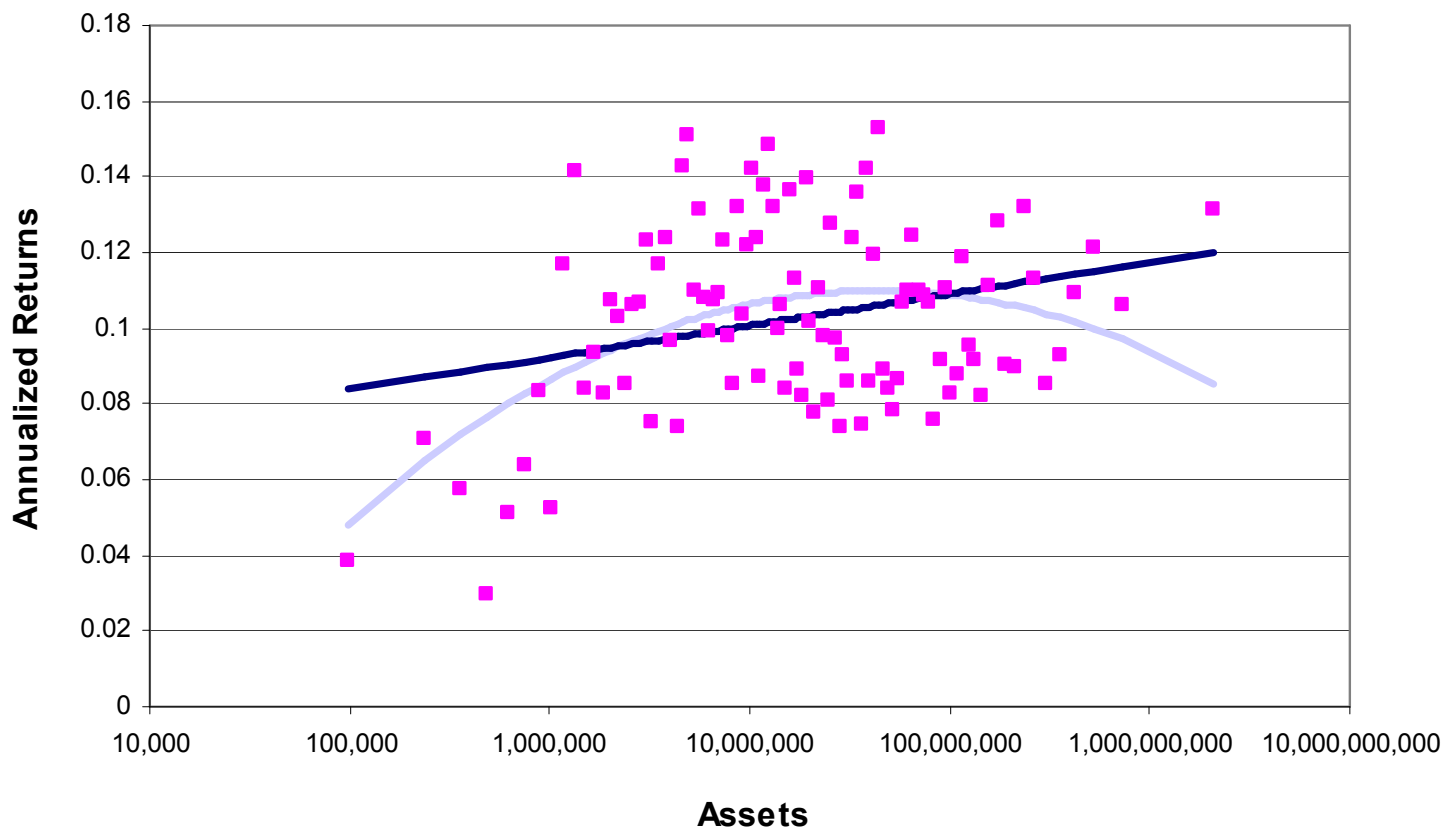




\section{EXHIBIT 17}

\section{Regression results of fund sizes versus annualized returns}

\begin{tabular}{lrrrr}
\hline Dependent variable & Annualized Returns \\
\hline Linear regression & \multicolumn{5}{c}{} \\
\hline Independent variables & Coefficient & Std. Error & t-Statistic & Prob. \\
\hline C & 0.0419 & 0.0211 & 1.9849 & 0.0500 \\
LOG(ASSETS) & 0.0036 & 0.0013 & 2.8890 & 0.0048 \\
& & & & \\
R-squared & 0.0785 & Adjusted R-squared & 0.0691 \\
\hline & & & & \\
Quadratic regression & & & & \\
\hline Independent variables & Coefficient & Std. Error & t-Statistic & Prob. \\
\hline C & -0.4024 & 0.1274 & -3.1591 & 0.0021 \\
LOG(ASSETS) & 0.0582 & 0.0155 & 3.7567 & 0.0003 \\
LOG(ASSETS)^2 & -0.0017 & 0.0005 & -3.5321 & 0.0006 \\
& & & & \\
R-squared & 0.1835 & Adjusted R-squared & 0.1667 \\
\hline
\end{tabular}

The funds are ranked according to their fund sizes and 100 asset percentiles are built in each month. In the linear regression the logarithm of the average assets of each of the 100 percentiles are regressed on the average annualized returns. In the quadratic regression the logarithm of the assets and squared logarithm of the assets are regressed on the average annualized returns. 


\section{EXHIBIT 18}

Log of asset sizes versus annualized standard deviations

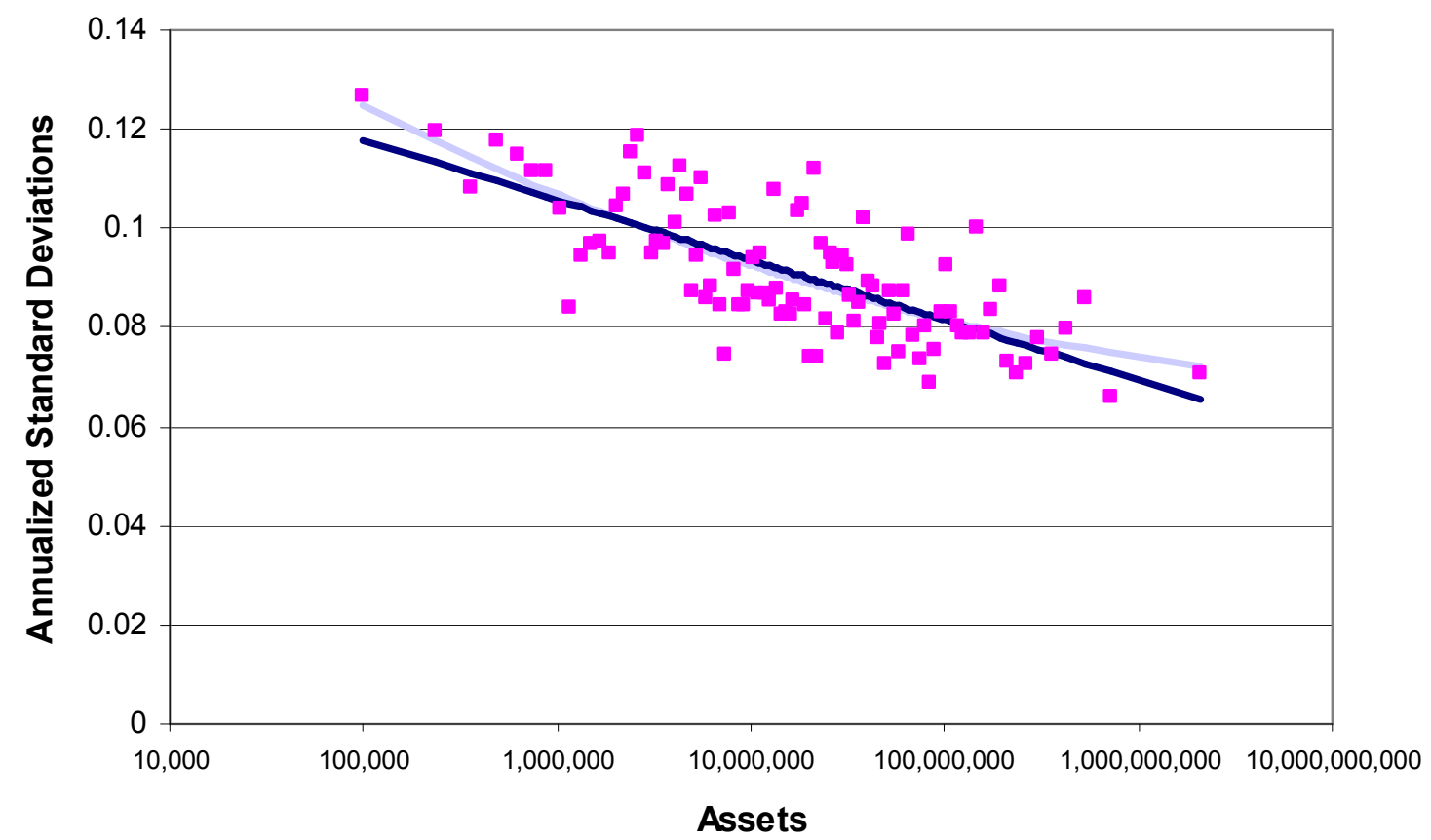




\section{EXHIBIT 19}

\section{Regression results of fund sizes versus standard deviations}

\begin{tabular}{lrrrr}
\hline Dependent variable & \multicolumn{1}{l}{ Annualized Standard Deviations } \\
\hline Linear regression & & & \\
\hline Independent variables & Coefficient & Std. Error & t-Statistic & Prob. \\
\hline C & 0.1783 & 0.0081 & 22.1331 & 0.0000 \\
LOG(ASSETS) & -0.0053 & 0.0005 & -10.9284 & 0.0000 \\
& & & & \\
R-squared & 0.1165 & Adjusted R-squared & 0.1074 \\
\hline & & & & \\
Quadratic regression & & & & \\
\hline Independent variables & Coefficient & Std. Error & t-Statistic & Prob. \\
\hline C & 0.2636 & 0.0509 & 5.1823 & 0.0000 \\
LOG(ASSETS) & -0.0157 & 0.0062 & -2.5420 & 0.0126 \\
LOG(ASSETS) 2 & 0.0003 & 0.0002 & 1.6974 & 0.0928 \\
& & & & \\
R-squared & 0.5493 & Adjusted R-squared & 0.5447 \\
\hline
\end{tabular}

The funds are ranked according to their fund sizes and 100 asset percentiles are built in each month. In the linear regression the logarithm of the average assets of each of the 100 percentiles are regressed on the standard deviations of the funds. In the quadratic regression the logarithm of the assets and squared logarithm of the assets are regressed on the standard deviations. 


\section{EXHIBIT 20}

Log of asset sizes versus annualized Sharpe Ratios

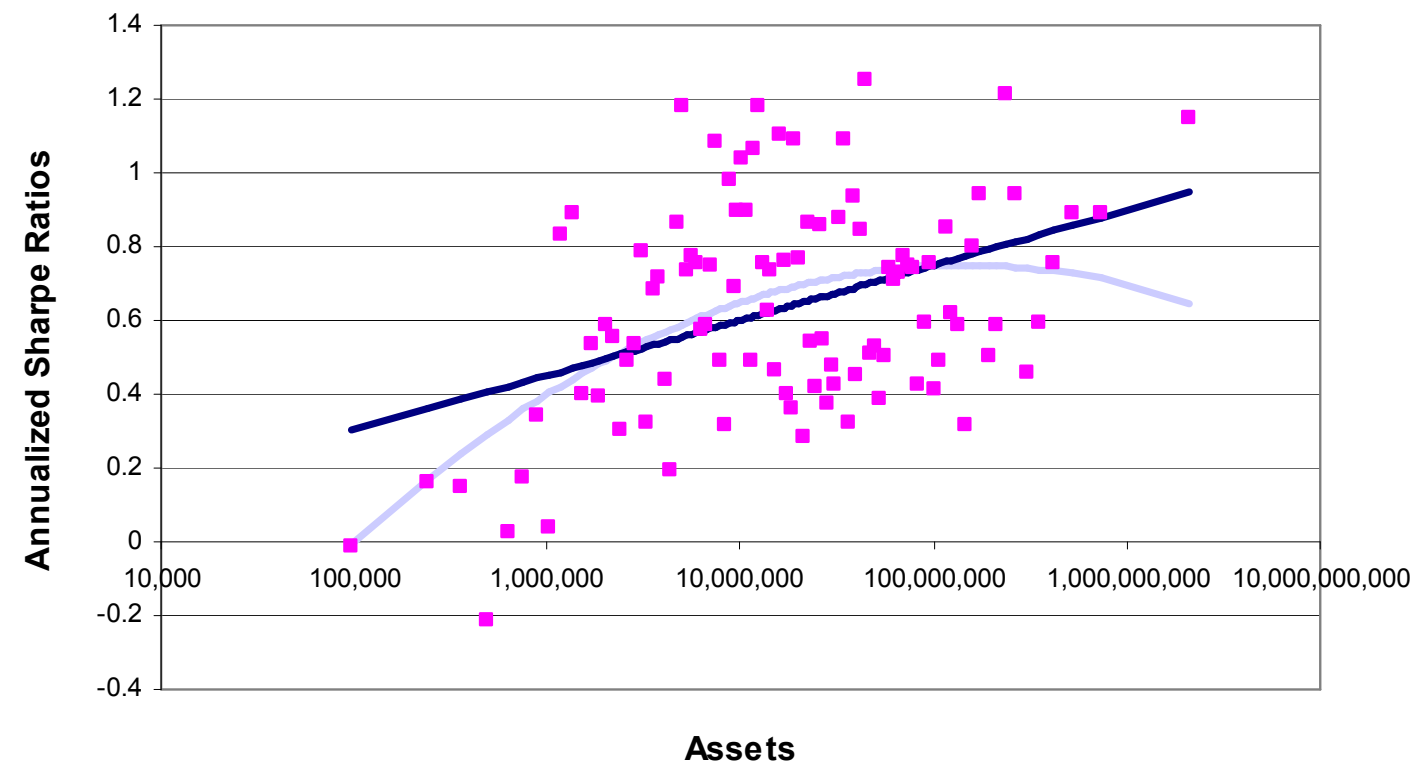




\section{EXHIBIT 21}

\section{Regression results of fund sizes versus Sharpe Ratios}

\begin{tabular}{|c|c|c|c|c|}
\hline Dependent variable & \multicolumn{4}{|c|}{ Annualized Sharpe Ratios } \\
\hline \multicolumn{5}{|l|}{ Linear regression } \\
\hline Independent variables & Coefficient & Std. Error & t-Statistic & Prob. \\
\hline C & -0.4435 & 0.2375 & -1.8676 & 0.0648 \\
\hline LOG(ASSETS) & 0.0648 & 0.0142 & 4.5679 & 0.0000 \\
\hline R-squared & 0.1755 & \multicolumn{2}{|c|}{ Adjusted R-squared } & 0.1671 \\
\hline \multicolumn{5}{|l|}{ Quadratic regression } \\
\hline Independent variables & Coefficient & Std. Error & t-Statistic & Prob. \\
\hline C & -4.2424 & 1.4704 & -2.8852 & 0.0048 \\
\hline LOG(ASSETS) & 0.5313 & 0.1789 & 2.9703 & 0.0038 \\
\hline LOG(ASSETS)^2 & -0.0141 & 0.0054 & -2.6160 & 0.0103 \\
\hline R-squared & 0.2299 & \multicolumn{2}{|c|}{ Adjusted R-squared } & 0.2140 \\
\hline
\end{tabular}

The funds are ranked according to their fund sizes and 100 asset percentiles are built in each month. In the linear regression the logarithm of the average assets of each of the 100 percentiles are regressed on the Sharpe Ratios. In the quadratic regression the logarithm of the assets and squared logarithm of the assets are regressed on the Sharpe Ratios. 


\section{EXHIBIT 22}

\section{Log of asset sizes versus annualized alphas}

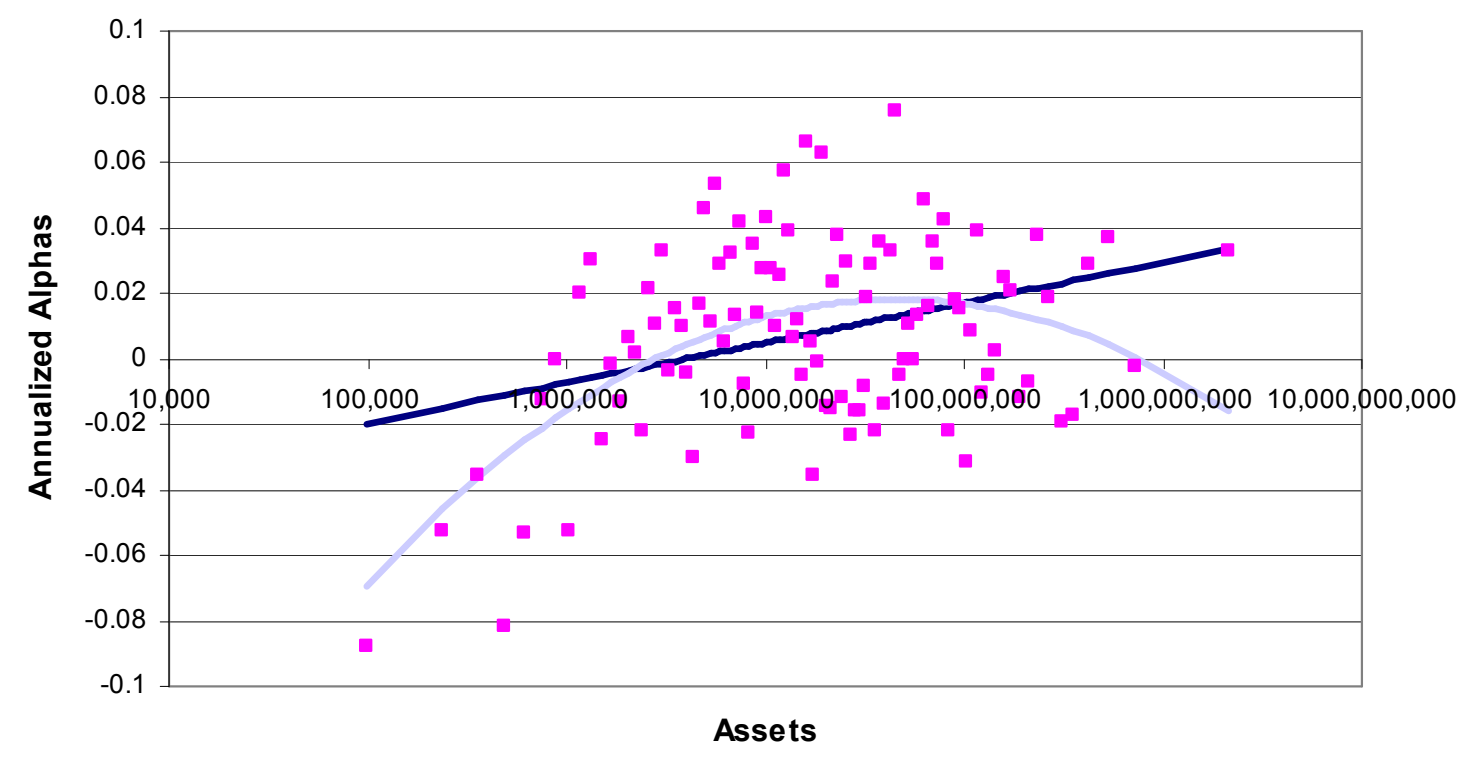

The alphas are derived from excess returns and a multi asset class factor model with three factors. The factors are the Goldman Sachs Commodity Index, the Wilshire Microcap Index and the Lehman Aggregate Bond Index. 


\section{EXHIBIT 23}

Regression results of fund sizes versus annualized alphas

Dependent variable Annualized Alphas (3-factor model)

Linear regression

\begin{tabular}{lrrrr}
\hline Independent variables & Coefficient & Std. Error & t-Statistic & \multicolumn{1}{c}{ Prob. } \\
\hline C & -0.0807 & 0.0247 & -3.2632 & 0.0015 \\
LOG(ASSETS) & 0.0053 & 0.0015 & 3.5939 & 0.0005 \\
R-squared & 0.1165 & Adjusted R-squared & 0.1074 \\
\hline
\end{tabular}

Quadratic regression

\begin{tabular}{|c|c|c|c|c|}
\hline Independent variables & Coefficient & Std. Error & $\mathrm{t}$-Statistic & Prob. \\
\hline C & -0.7024 & 0.1450 & -4.8442 & 0.0000 \\
\hline LOG(ASSETS) & 0.0817 & 0.0176 & 4.6293 & 0.0000 \\
\hline LOG(ASSETS) $)^{\wedge} 2$ & -0.0023 & 0.0005 & -4.3413 & 0.0000 \\
\hline R-squared & 0.2602 & \multicolumn{2}{|c|}{ Adjusted R-squared } & 0.2449 \\
\hline
\end{tabular}

The alphas are derived from excess returns and a multi asset class factor model with three factors. The factors are the Goldman Sachs Commodity Index, the Wilshire Microcap Index and the Lehman Aggregate Bond Index. For the regression analysis the funds are ranked according to their fund sizes and 100 asset percentiles are built in each month. In the linear regression the logarithm of the average assets of each of the 100 percentiles are regressed on the alphas derived from the 3-factor model. In the quadratic regression the logarithm of the assets and squared logarithm of the assets are regressed on the alphas derived from the 3 -factor model. 


\section{EXHIBIT 24}

\section{Regression results of fund sizes versus annualized alphas}

\begin{tabular}{lrrrr}
\hline Dependent variable & Annualized Alphas (3-factor model with $\mathrm{MSCl}$ ) \\
\hline Linear regression & & & & \\
\hline Independent variables & Coefficient & Std. Error & t-Statistic & Prob. \\
\hline C & -0.0716 & 0.0252 & -2.8403 & 0.0055 \\
LOG(ASSETS) & 0.0059 & 0.0015 & 3.8979 & 0.0002 \\
R-squared & 0.1342 & Adjusted R-squared & 0.1254 \\
\hline
\end{tabular}

The alphas are derived from excess returns and a multi asset class factor model with three factors. The factors are the Goldman Sachs Commodity Index, the Lehman Aggregate Bond Index and the MSCI World. For the regression analysis the funds are ranked according to their fund sizes and 100 asset percentiles are built in each month. In the linear regression the logarithm of the average assets of each of the 100 percentiles are regressed on the alphas derived from the 3-factor model. In the quadratic regression the logarithm of the assets and squared logarithm of the assets are regressed on the alphas derived from the 3 -factor model. 


\section{EXHIBIT 25}

\section{Regression results of fund sizes versus annualized alphas}

\begin{tabular}{lrrrr}
\hline Dependent variable & Annualized Alphas (2-factor model) & \\
\hline Linear regression & & & & \\
\hline Independent variables & Coefficient & Std. Error & t-Statistic & Prob. \\
\hline C & -0.0251 & 0.0216 & -1.1618 & 0.2481 \\
LOG(ASSETS) & 0.0031 & 0.0013 & 2.4129 & 0.0177 \\
R-squared & 0.0561 & Adjusted R-squared & 0.0464 \\
\hline
\end{tabular}

The alphas are derived from excess returns and a multi asset class factor model with two factors. The factors are the Goldman Sachs Commodity Index and the Wilshire Microcap Index For the regression analysis the funds are ranked according to their fund sizes and 100 asset percentiles are built in each month. In the linear regression the logarithm of the average assets of each of the 100 percentiles are regressed on the alphas derived from the 2factor model. In the quadratic regression the logarithm of the assets and squared logarithm of the assets are regressed on the alphas derived from the 2-factor model. 